\title{
ANÁLISE SOCIOAMBIENTAL DE BACIA HIDROGRÁFICA COM USINAS HIDROELÉTRICAS
}

\author{
environmental analysis of watershed with hydroelectric
}

\author{
Júlio César Ibiapina Neres* \\ Manuel Eduardo Ferreira** \\ Nelson Jorge da Silva Júnior***
}

\begin{abstract}
Resumo
No Brasil, a maior parte da energia elétrica disponível é proveniente de grandes usinas hidroelétricas, cuja construção e implantação envolve uma série de mudanças sócio-ambientais. Ultimamente, a necessidade de mitigação de impactos ambientais relacionados à obtenção de energia e à busca por sustentabilidade geram discussões mundiais, que envolvem interesses ambientais, políticos, sociais e econômicos. Na bacia hidrográfica do rio Tocantins tais demandas não são diferentes, onde vários projetos de geração de energia, a partir de usinas hidroelétricas, necessitam de um planejamento para o desenvolvimento sustentável das atividades futuras e em andamento. Neste estudo, foi realizado o mapeamento do uso da terra nos municípios com usinas hidroelétricas no vale do rio Tocantins, através de ferramentas de geoprocessamento e sensoriamento remoto, como subsidio para compreensão dos processos socioambientais. Dentre os municípios avaliados, os do estado do Maranhão apresentaram as maiores desigualdades sociais. A construção de usinas hidroelétricas não é garantia de benefícios sociais, apesar ser constatada uma associação das mesmas com o desenvolvimento local dos municípios. Por outro lado, deve-se considerar os impactos ambientais atrelados a estes empreendimentos, normalmente acompanhados por uma significativa redução da cobertura vegetal nativa (fisionomias de savana e floresta) dentro do período analisado.
\end{abstract}

Palavras-chave: Rio Tocantins, Análise socioambiental, Usinas hidroelétricas, Bioma Cerrado.

\begin{abstract}
Most of the electric energy available in Brazil comes from large hydroelectric power plants. The constructions of these hydroelectric involve a series of social-environmental changes. The mitigation of the environmental impacts related to the energy production and search for sustainability has normally generated global discussions with environmental, social and economic interests. Therefore, all projects of energy generation from hydroelectric plants need a planning that aims the sustainable development of future and ongoing activities. In this work we performed a historical map over the Tocantins river valley using remote sensing and GIS techniques as a subsidy to understanding the social-environmental impacts in this region. Between the municipalities analyzed, those from the state of Maranhão have presented the highest social inequalities. Finally, the construction of hydroelectric plants is not a guarantee of social benefits, although be verified a certain association with the development of these municipalities. Moreover, it should be consider the environmental impacts linked to these developments, usually accompanied by a significant reduction of the native vegetation cover (savanna and forest physiognomies) within the period analyzed.
\end{abstract}

Key words: Tocantins river, Social-environmental analysis, Hydroelectric, Cerrado biome.

\section{Resumen}

En Brasil, la mayor parte de la energía eléctrica disponible es proveniente de grandes usinas hidroeléctricas, cuya construcción e implementación involucra una serie de cambios socio-ambientales. Últimamente, la necesidad de mitigación de impactos ambientales relacionados a la obtención de energía y la búsqueda de sustentabilidad generan discusiones mundiales, que involucran intereses ambientales, políticos, sociales y económicos. En la cuenca hidrográfica del río Tocantins tales demandas no son diferentes, donde varios proyectos de generación de energía, a partir de usinas hidroeléctricas, necesitan de un planeamiento para el desarrollo sustentable de las actividades futuras y en andamiento. En el estudio, fue realizado el mapeo del uso de la tierra en los municipios con usinas hidroeléctricas en el vale del Río Tocantins, a través de herramientas de geo-procesamiento, y detección remota, con subsidio para comprensión de los procesos socio ambientales. Entre los municipios evaluados, los del Estado de Maranhão presentaron la mayores desigualdad social. La construcción de usinas hidroeléctricas no es garantía de beneficios sociales, a pesar de ser constatada una asociación de las mismas con el desarrollo local de los municipios. Por otro lado se debe considerar los impactos ambientales que traen estos emprendimientos, normalmente acompañados por una significativa reducción de la cobertura vegetal nativa (sabana y bosque) dentro del periodo analizado.

Palabras clave: Rio Tocantins, Análisis socioambiental, Usinas hidroeléctricas, Bioma cerrado.

(*) Prof. Msc. da Fundação de Desenvolvimento Educacional de Guaraí - Faculdade Guaraí, CEP: 77.700-000, Guaraí (TO) - Brasil - jcneres@gmail.com

(**) Prof. Dr. do Instituto de Estudos Sócio-Ambientais - Universidade Federal de Goiás, Cx. Postal 131 - CEP: 74.001-970 - Goiânia (GO) - Brasil - manuel@iesa.ufg.br

(***) Prof. Dr. do Mestrado em Ciências Ambientais e Saúde - Pontifícia Universidade Católica de Goiás - Goiás, Cx. Postal 86 - CEP: 74.605-010 - Goiânia - GO - Brasil - herp@terra.com.br 


\section{INTRODUÇÃO}

Nos últimos anos, poucos assuntos têm despertado tanta atenção quanto às questões referentes ao meio ambiente, incluindo as recentes discussões sobre as mudanças climáticas e perda de biodiversidade global. No Brasil, por exemplo, este bem-lembrado ambiente natural vem sofrendo com o aumento das demandas por energia, alimentos e outros bens de consumo (durável e não-durável), demandas estas em forte ascensão a partir da estabilização da economia/globalização (COSTA; PRATES, 2005).

Neste contexto, marcado pela intensificação da industrialização e urbanização do país, a oferta por recursos energéticos tornou-se um dos fatores mais limitantes para tal crescimento da produção e consumo, de forma que hoje a prioridade seja a exploração de novas fontes de energia (ex.: biocombustíveis), bem como a expansão do atual complexo energético brasileiro (ex.: novas hidroelétricas e a descoberta recente de petróleo na região oceânica do Pré-sal).

Especificamente sobre a energia proveniente de fontes limpas (sem emissão de gases poluentes) e renováveis, o setor hidroelétrico ainda responde por grande parte da energia consumida no país (MME, 2006), considerando também o nosso elevado potencial hídrico natural. Como qualquer setor em expansão, surgem nesta fase o interesse de empresas multinacionais em subsidiar empreendimentos desse porte, levando o Brasil a permanecer, em detrimento de outras alternativas (solar, nuclear e eólica), com uma maior produção de energia através da hidroeletricidade.

No país, a hidroeletricidade é a base de suprimento energético (MULLER, 1995), respondendo por cerca de $80 \%$ da geração de energia, e por $82,8 \%$ da eletricidade consumida (ANEEL, 2007). No atual estágio de desenvolvimento, esta fonte é considerada como o melhor custo-benefício em termos técnicos e econômicos, em face dos riscos ambientais e dos custos, se comparada com a energia nuclear ou eólica, por exemplo (ROSA, 1995).

Apesar de ser uma fonte de energia praticamente limpa, a construção de uma usina hidroelétrica normalmente trás em sua concepção alguns impactos ao meio ambiente, sendo um deles a necessidade de um reservatório (tamanhos variados), com a respectiva contenção de um rio de importância significativa para uma bacia hidrográfica. Ultimamente, o Brasil revive este embate socioambiental com a construção da usina de Belo Monte, no Rio Xingu (Pará), com fortes argumentos favoráveis e contrários à sua construção. Por um lado, Belo Monte, que será a 2a maior usina hidrelétrica do país (atrás apenas da binacional Itaipu), deve suprir, ainda que a um custo ambiental maior, a atual demanda no Brasil por energia elétrica, concomitantemente com a geração de empregos e desenvolvimento econômico, sobretudo no estado do Pará. Por outro, alagará uma área expressiva na Amazônia (um reservatório com cerca de $500 \mathrm{~km} 2$ ), com implicações no habitat de várias espécies da fauna e flora desta região, no deslocamento de comunidades indígenas e de agricultores, além de uma contribuição na emissão de gases de efeito-estufa (CH4).

No cenário nacional, o Rio Tocantins figura dentre os maiores sistemas hidrográficos do país (sistema Araguaia-Tocantins), passando por vários estados brasileiros (ANA, 2006), com diversos projetos implantados para a geração de energia hidroelétrica. Nesta bacia, as condições físico-hidrográficas facilitam a multiplicação de reservatórios e quedas de água.

Ainda que um planejamento prévio seja exigido para a implantação de uma nova usina hidroelétrica, os impactos físicos e sociais causados nas áreas modificadas ainda são pouco estudados, tornando-se de extrema importância a realização de estudos bem estruturados acerca das transformações que sucedem a sua construção.

Neste sentido, o presente estudo teve por objetivo caracterizar os impactos socioambientais nos municípios inseridos na bacia hidrográfica do Rio Tocantins, e que porventura tenham, ao longo de quase três décadas (1980 a 2006), recebido uma usina hidroelétrica em seu plantel energético. Para tanto, uma análise comparativa foi realizada entre tais municípios, considerando-se os dados censitários (Índice de Desenvolvimento Humano, pobreza e concentração de renda), além de dados acerca da cobertura vegetal e uso da terra, providos por imagens de satélites no mesmo período. 


\section{MATERIAIS E MÉTODOS}

\section{Área de Estudo}

A bacia hidrográfica do Rio Tocantins, compreendida em parte do Centro-Oeste e Norte do Brasil, possui uma área de $918.273 \mathrm{~km} 2$ (11\% do território nacional), abrangendo os estados de Goiás (e o Distrito Federal), Mato Grosso, Tocantins, Maranhão e Pará.

Para este estudo em específico, foi limitada uma área da bacia hidrográfica do Tocantins (182.401 km2), envolvendo os estados de Goiás, Maranhão, Pará e Tocantins (Figura 1), por esta possuir vários empreendimentos hidrelétricos em operação, tais como as usinas de Tucuruí, Lajeado, Serra da Mesa, Cana-Brava e Peixe Angical (Figura 2).

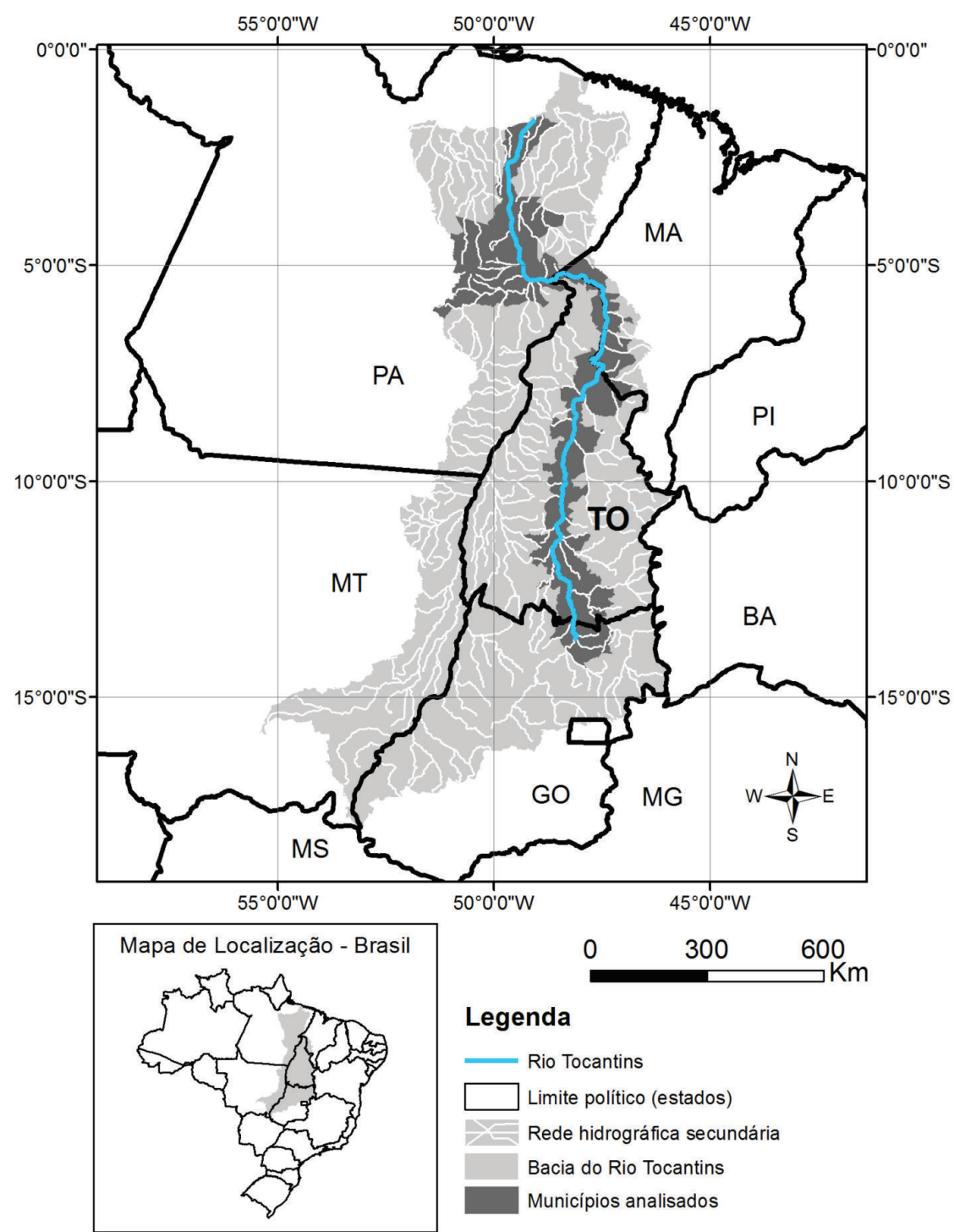

Figura 1 - Localização da área de estudo, com destaque para a bacia hidrográfica do Rio Tocantins, seu curso hidrográfico principal (Rio Tocantins) e os municípios analisados.

À época de realização deste estudo, as usinas de São Salvador e Estreito estavam em construção, somadas aos futuros projetos das usinas de Ipueiras, Tupiratins e Serra Quebrada (Figura 2). Ao todo, esses empreendimentos configuram um significativo crescimento de energia para a expansão do setor elétrico do país.

A bacia hidrográfica do Rio Tocantins tem origem no Planalto Central (em Goiás), acerca de 1000 metros de altitude, formada pelos rios das Almas e Maranhão, com extensão total de $1960 \mathrm{~km}$ até sua foz no oceano Atlântico. Entre seus principais afluentes, destaca-se o Rio Araguaia, com 
2600 km de extensão, onde se encontra a Ilha do Bananal, maior ilha fluvial do mundo. Na margem direita, destacam-se os rios Bagagem, Tocantizinho, Paranã dos Sonos, Manoel Alves e Farinha. Na margem esquerda, o rio Santa Teresa e Itacaúnas.

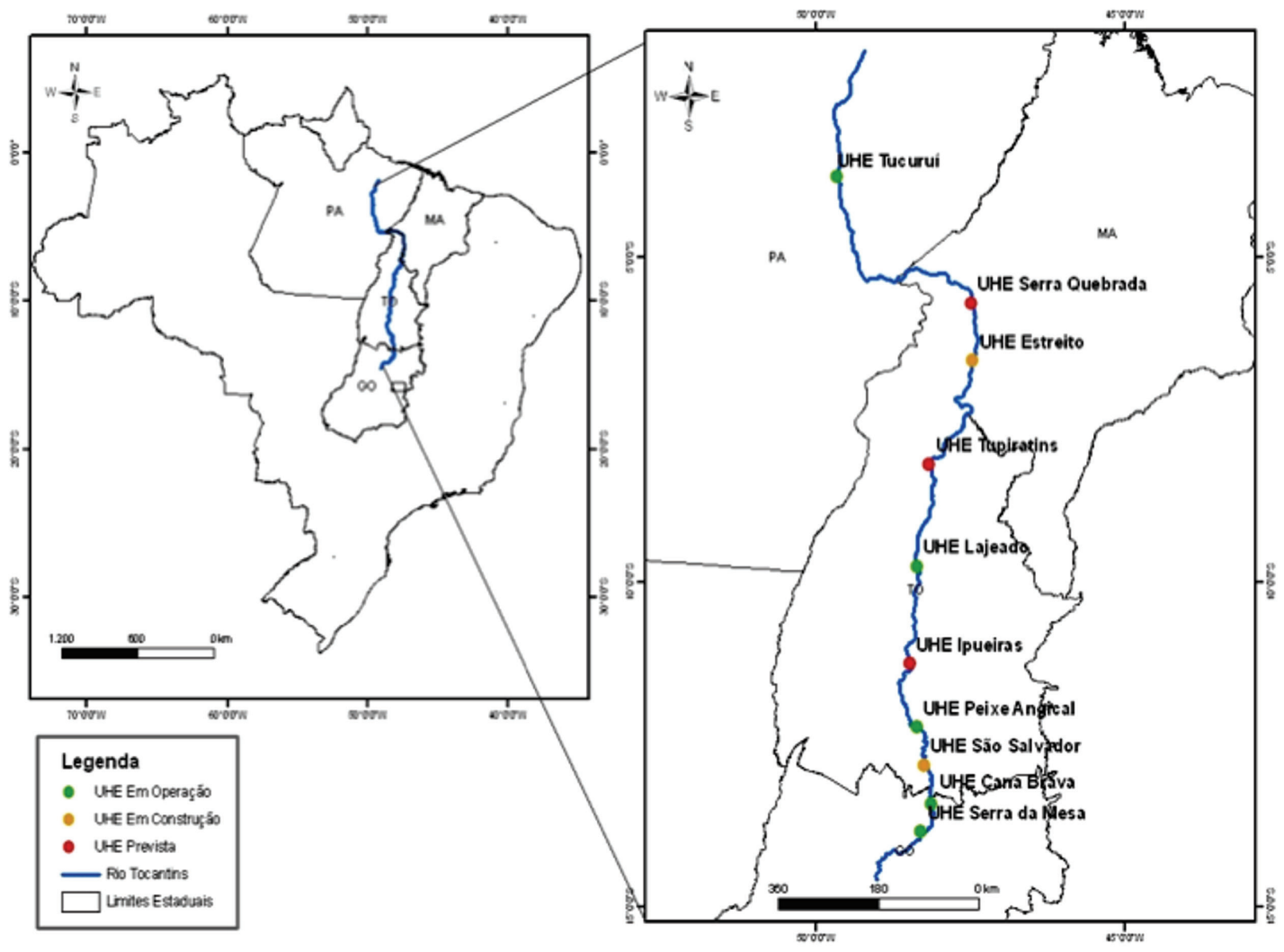

Figura 2 - Mapa da bacia hidrográfica do Rio Tocantins, indicando os Estados e a localização das usinas hidroelétricas no Rio Tocantins

\section{Organização dos Dados}

Num primeiro momento, foram selecionados os 43 municípios envolvidos diretamente pelos reservatórios das usinas hidroelétricas no rio Tocantins. 8 municípios pertencem ao estado de Goiás, 5 no estado do Maranhão, 7 no estado do Pará e 23 no Estado do Tocantins (Tabela 1).

\section{Dados de imagens de satélite}

A segunda etapa do trabalho consistiu no mapeamento dos remanescentes de vegetação da área de estudo, através da interpretação de imagens de satélite. Foram utilizadas imagens do satélite Landsat (sensor MSS), obtidas ao longo dos anos de 1979 a 1981 (Tabela 2), e imagens do satélite sino-brasileiro CBERS 2 (sensor CCD), referentes ao ano de 2006 (Tabela 3).

As imagens de satélite são referentes aos meses de julho, agosto e setembro, correspondente à estação seca nesta região. As cenas Landsat - MSS e CBERS 2 - CCD foram adquiridas no portal de dados do Instituto Nacional de Pesquisas Espaciais - INPE (http://www.dgi.inpe.br:80/CDSR).

Ao todo, foram obtidas 69 imagens, entre 1979 e 2006, georreferenciadas e organizadas em mosaicos, de acordo com o ano: mosaico referente a 1980 (dados de 1979 a 1981) e 2006, cobrindo dois momentos históricos da bacia do Rio Tocantins, conforme ilustrado na figura 3.

Para compor o mosaico e melhorar o processo de visualização, as bandas espectrais de cada cena foram associadas ao sistema de cores RGB. Assim, a composição utilizada para o sensor Landsat MSS foi a RGB 5/4/3 (correspondente às bandas espectrais do Infravermelho médio, Infravermelho próximo e Vermelho). Para o sensor CBERS 2 - CCD foi a RGB 3/4/2 (correspondente às bandas espectrais do Vermelho, Infravermelho próximo e Verde). 
A resolução espacial para as imagens MSS, mais antigas, é de 80 metros, enquanto as imagens do CBERS apresentam 20 metros de resolução. Ao final, e por esta diferença de resolução, determinamos uma escala média de mapeamento de 1:100.000.

Tabela 1 - Municípios envolvidos pelos reservatórios das usinas hidroelétricas no Rio Tocantins.

\begin{tabular}{l|l}
\hline \multicolumn{1}{c|}{ Goiás } & \multicolumn{1}{c}{ Tocantins } \\
\hline Campinaçu & Aguiarnopólis \\
\hline Campinorte & Babaçulandia \\
\hline Cavalcante & Barra do Ouro \\
\hline Colinas do Sul & Bom Jesus do Tocantins \\
\hline Minaçu & Brejinho de Nazaré \\
\hline Niquelândia & Filadélfia \\
\hline São Luis do Norte & Ipueiras \\
\hline Uruaçu & Itaguatins \\
\hline \multicolumn{1}{c}{ Maranhão } & Itapiratins \\
\hline Campestre do Maranhão & Lajeado \\
\hline Carolina & Maurilândia do Tocantins \\
\hline Estreito & Miracema do Tocantins \\
\hline Porto Franco & Palmas \\
\hline Ribamar Fiquené & Palmeirópolis \\
\hline \multicolumn{1}{c}{ Pará } & Palmeirante \\
\hline Breu Branco & Paranã \\
\hline Itupiranga & Pedro Afonso \\
\hline Jacundá & Peixe \\
\hline Marabá & Porto Nacional \\
\hline Novo Repartimento & São Salvador \\
\hline São João do Araguaia & Tocantinópolis \\
\hline Tucuruí & Tupirama \\
\cline { 2 - 2 } & Tupiratins \\
\hline &
\end{tabular}

Fonte: IBGE.

Tabela 2 - Órbita/ponto e datas das imagens adquiridas pelo sensor Landsat - MSS (20 cenas). Valores entre 237 e 241 representam as órbitas; valores entre 62 e 70 representam os pontos

Visando a quantificação da vegetação remanescente em cada um dos dois mosaicos, algumas técnicas de processamento digital de imagens foram adotadas, sendo a primeira delas a de realce dos alvos naturais por NDVI (Índice de Vegetação da Diferença Normalizada); o NDVI possui a finalidade de realçar a vegetação "saudável" (i.e., elevada atividade fotossintética), bem como as áreas antropizadas (normalmente associadas ao solo exposto, agricultura, queimadas e áreas urbanas).

Tabela 2. Órbita/ponto e datas das imagens adquiridas pelo sensor Landsat - MSS

Valores entre 237 e 241 representam as órbitas; valores entre 62 e 70 representam os pontos

\begin{tabular}{l|c|c|c|c|c}
\hline & $\mathbf{2 3 7}$ & $\mathbf{2 3 8}$ & $\mathbf{2 3 9}$ & $\mathbf{2 4 0}$ & $\mathbf{2 4 1}$ \\
\hline $\mathbf{6 2}$ & & & & $25 / 06 / 1980$ & \\
\hline $\mathbf{6 3}$ & & & $06 / 08 / 1981$ & $07 / 06 / 1979$ & $24 / 07 / 1980$ \\
\hline $\mathbf{6 4}$ & & $03 / 08 / 1981$ & $06 / 06 / 1981$ & $25 / 06 / 1980$ & $03 / 07 / 81$ \\
\hline $\mathbf{6 5}$ & & $01 / 08 / 1980$ & $06 / 06 / 1979$ & & \\
\hline $\mathbf{6 6}$ & & $23 / 08 / 1981$ & $06 / 08 / 1981$ & & \\
\hline $\mathbf{6 7}$ & & $23 / 06 / 1979$ & $29 / 08 / 1980$ & & \\
\hline $\mathbf{6 8}$ & & $30 / 06 / 1981$ & $19 / 07 / 1981$ & & \\
\hline $\mathbf{6 9}$ & $26 / 12 / 1981$ & $25 / 05 / 1981$ & & & \\
\hline $\mathbf{7 0}$ & $09 / 09 / 1981$ & $05 / 08 / 1981$ & & & \\
\hline
\end{tabular}

A segunda técnica, visando a classificação temática das imagens NDVI, foi o chamado "Fatiamento" (Slice), onde 4 classes temáticas foram geradas, de acordo com o valor de NDVI (ranges); 
um agrupamento dessas classes, chamado aqui de "Reclassificação" (Reclass) foi realizado em seguida, com o objetivo de simplificar os mapas de uso da terra em duas classes: remanescentes e uso antrópico. Um filtro de classificação (Majority), com o objetivo de se eliminar vazios entre polígonos, foi aplicado nesta etapa.

Tabela 3 - Órbita/ponto e data das imagens adquiridas pelo sensor CBERS 2 - CCD (49 cenas). Valores entre 157 e 163 representam as órbitas; valores entre 102 e 117 representam os pontos

\begin{tabular}{l|c|c|c|c|c|c|c}
\hline & $\mathbf{1 5 7}$ & $\mathbf{1 5 8}$ & $\mathbf{1 5 9}$ & $\mathbf{1 6 0}$ & $\mathbf{1 6 1}$ & $\mathbf{1 6 2}$ & $\mathbf{1 6 3}$ \\
\hline $\mathbf{1 0 2}$ & & & & & $04 / 07 / 2006$ & $01 / 07 / 2006$ & \\
\hline $\mathbf{1 0 3}$ & & & & & & $01 / 07 / 2006$ & \\
\hline $\mathbf{1 0 4}$ & & & & & $04 / 07 / 2006$ & $01 / 07 / 2006$ & $24 / 07 / 2006$ \\
\hline $\mathbf{1 0 5}$ & & & & $07 / 07 / 2006$ & $04 / 07 / 2006$ & $01 / 07 / 2006$ & $24 / 07 / 2006$ \\
\hline $\mathbf{1 0 6}$ & & & $05 / 08 / 2006$ & $07 / 07 / 2006$ & $04 / 07 / 2006$ & $01 / 07 / 2006$ & $24 / 07 / 2006$ \\
\hline $\mathbf{1 0 7}$ & & $08 / 08 / 2006$ & $05 / 08 / 2006$ & $07 / 07 / 2006$ & $04 / 07 / 2006$ & $27 / 07 / 2006$ & $24 / 07 / 2006$ \\
\hline $\mathbf{1 0 8}$ & & $08 / 08 / 2006$ & $05 / 08 / 2006$ & $07 / 07 / 2006$ & & & \\
\hline $\mathbf{1 0 9}$ & & $03 / 09 / 2006$ & $05 / 08 / 2006$ & $07 / 07 / 2006$ & & & \\
\hline $\mathbf{1 1 0}$ & & & $05 / 08 / 2006$ & $11 / 07 / 2006$ & & & \\
\hline $\mathbf{1 1}$ & & $08 / 08 / 2006$ & $05 / 08 / 2006$ & $11 / 07 / 2006$ & & & \\
\hline $\mathbf{1 1 3}$ & & & $05 / 08 / 2006$ & $07 / 07 / 2006$ & & & \\
\hline $\mathbf{1 1 4}$ & $11 / 08 / 2006$ & $29 / 09 / 2006$ & $05 / 08 / 2006$ & & & & \\
\hline $\mathbf{1 1 5}$ & $11 / 08 / 2006$ & $29 / 09 / 2006$ & $05 / 08 / 2006$ & & & & \\
\hline $\mathbf{1 1 6}$ & $11 / 08 / 2006$ & $08 / 09 / 2006$ & $05 / 08 / 2006$ & & & & \\
\hline $\mathbf{1 1 7}$ & $11 / 08 / 2006$ & $08 / 09 / 2006$ & $05 / 08 / 2006$ & & & & \\
\hline
\end{tabular}
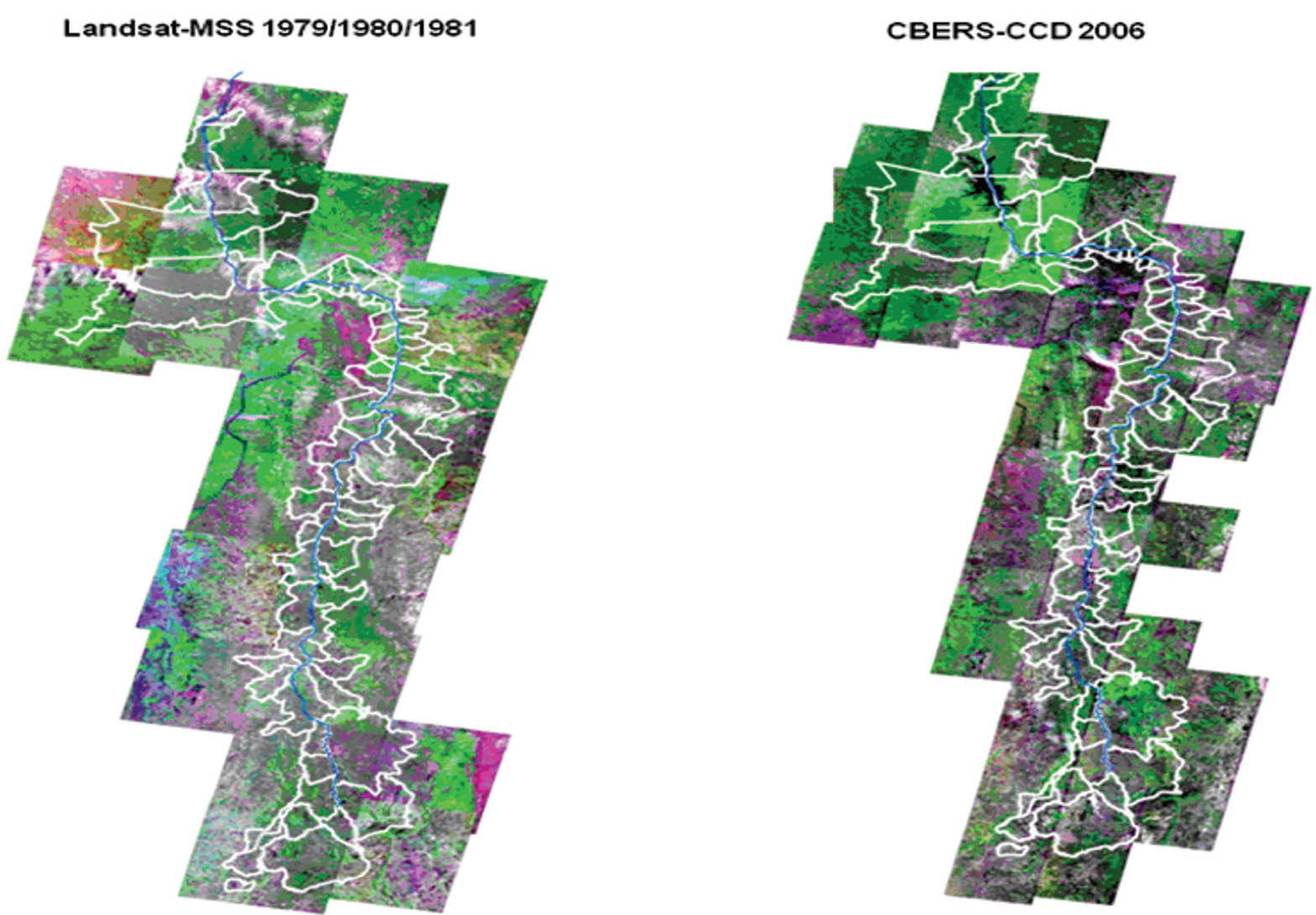

Figura 3 - Mosaicos das cenas Landsat - MSS e CBERS 2 - CCD empregadas no mapeamento da área de estudo, entre 1980* e 2006. Os limites dos municípios estão sobrepostos na cor branca. (*entre 1979 e 1981). 
Ao final, foi gerado um vetor (processo de poligonização) somente para a classe de remanescente (vegetação nativa), para então prosseguir com as análises quantitativas para área de estudo. Todas as tarefas mencionadas foram realizadas com os softwares ENVI e ArcGIS. A figura 4 ilustra as etapas aplicadas no processamento de cada uma das 69 imagens de satélite.

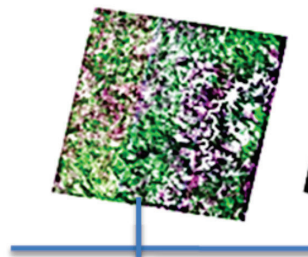

Imagem

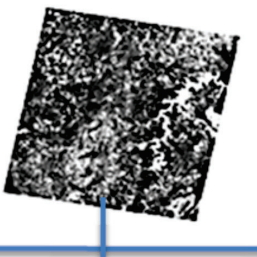

NDVI

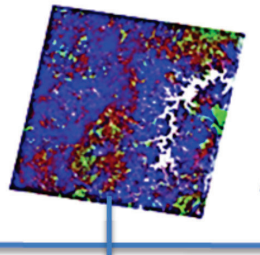

Classificação

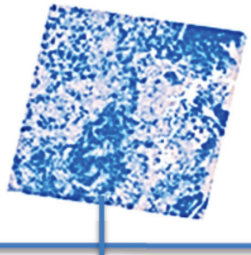

Edição 1

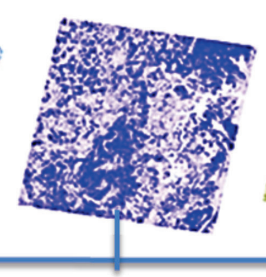

Edição 2

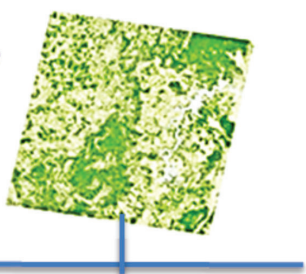

Mapa final (vetor)

Figura 4 - Da esquerda para a direita, exemplo das etapas de processamento aplicadas para cada uma das 69 cenas, ao final mosaicadas para a área de estudo: 1) Imagem de satélite (padrão de cores RGB - MIR/NIR/RED). 2) NDVI (geração do índice de vegetação). 3) Classificação (fatiamento por intervalos de valores do NDVI). 4) Edição 1 (reclassificação, em duas classes - uso e não-uso); 5) Edição 2 (filtro para preenchimento de pequenos vazios). 6) Mapa final (formato vetorial, com duas classes - uso e não-uso).

\section{Dados socioeconômicos}

Quanto aos dados socioeconômicos dos municípios, estes foram obtidos através do portal de dados do Programa das Nações Unidas para o Desenvolvimento (PNUD - Brasil), disponível para os anos de 1991 e 2000. As seguintes variáveis foram consideradas: Índice de Desenvolvimento Humano - IDH (1991 e 2000), Índice de Gini (1991 e 2000) e Índice de Pobreza (1991 e 2000). Os dados municipais do PNUD foram espacializados de acordo com o mapa político-administrativo municipal (base IBGE - 2000).

Sobre os índices empregados na análise, o IDH retrata o desenvolvimento de uma dada região ou sociedade por meio da síntese de três indicadores: renda per capita, educação e longevidade. O índice de Gini descreve a concentração de renda para uma dada sociedade, onde 0 (zero) representaria, de forma hipotética, uma renda igualmente distribuída entre os indivíduos, e 1, por sua vez, a concentração de toda a renda por um único individuo. $O$ índice de Pobreza indica a proporção de pessoas vivendo abaixo da linha de pobreza no Brasil, fixada em $\mathrm{R} \$$ de acordo com a metade do valor de um salário mínimo vigente no país (ex.: em dezembro de 2009, este valor seria de $\mathrm{R} \$ 232,50$ ).

\section{RESULTADOS E DISCUSSÃO}

\section{Análise da Cobertura Vegetal Nativa}

A análise temporal de imagens de satélite permitiu a identificação da dinâmica da paisagem nos municípios diretamente envolvidos com a construção das hidroelétricas, entre anos de 1980 e 2006, incluindo as taxas brutas de desmatamentos para cada período analisado, bem como a evolução dessa ao longo do tempo.

Para possibilitar a comparação dos remanescentes de Cerrado entre municípios com diferentes extensões territoriais, a área de cobertura vegetal foi normalizada em função da área de cada unidade política municipal (Equação 1), onde 0\% indica ausência de remanescentes, e 100\% indica total presença de remanescentes no município (ou seja, um Índice Normalizado de Remanescentes - INR)..

Equação (1):

(R/At) x 100

Onde: $\mathrm{R}=$ Área de remanescentes de Cerrado.

$\mathrm{At}=$ Área total do município. 


\section{Estado de Goiás}

Nos municípios presentes no estado de Goiás, envolvidos pelos empreendimentos hidroelétricos de Serra da Mesa e Cana-Brava, foi observado uma redução da cobertura vegetal nativa (Tabela 4) em poucos municípios, mais proeminente em Minaçu (34\% de perda). No geral, para uma significativa parte dos municípios, houve um pequeno acréscimo de vegetação, devido ao processo de regeneração da cobertura natural ou por reflorestamentos, caso de Campinorte ( $14 \%$ de acréscimo entre 1980 e 2006).

Nos casos onde a cobertura vegetal nativa pouco ou nada alterou, pode-se dizer que os empreendimentos hidroelétricos, incluindo a área alagada, não influenciaram de forma significativa na mudança da paisagem natural (em 1980, o uso da terra nestas áreas já estava instalado, sobretudo pela presença de pastagens nativas).

Tabela 4 - Quantificação da vegetação remanescente (INR) para os anos de 1980 e 2006, nos municípios envolvidos por empreendimentos hidroelétricos no Estado de Goiás

\begin{tabular}{l|c|c|c|c|c}
\hline \multirow{2}{*}{ MUNICÍPIOS } & & 1980 & & 2006 & \\
\cline { 2 - 6 } & Área mun. (ha) & Veg. nativa (ha) & $\%$ & Veg. nativa (ha) & $\%$ \\
\hline Campinaçu & 198.170 & 111.017 & 56 & 121.398 & 61 \\
\hline Campinorte & 107.210 & 40.831 & 38 & 55.806 & 52 \\
\hline Cavalcante & 697.950 & 319.848 & 46 & 327.299 & 47 \\
\hline Colinas do Sul & 171.450 & 101.053 & 59 & 108.817 & 63 \\
\hline Minaçu & 287.160 & 229.827 & 80 & 132.759 & 46 \\
\hline Niquelândia & 987.900 & 487.378 & 49 & 468.138 & 47 \\
\hline São Luis do Norte & 58.810 & 17.242 & 29 & 18.556 & 32 \\
\hline Uruaçu & 214.970 & 76.854 & 36 & 89.131 & 41 \\
\hline Total & 2.723 .620 & 1.384 .050 & 50,81 & 1.321 .904 & 48.53 \\
\hline
\end{tabular}

\section{Estado do Maranhão}

As transformações na cobertura vegetal nos 5 municípios do Estado do Maranhão, envolvidos pelo surgimento de usinas hidroelétricas no rio Tocantins, aconteceram de forma progressiva, ao longo dos 26 anos de análise, causando sensíveis mudanças na paisagem deste estado. A tabela 5 apresenta a quantificação da cobertura vegetal nestes municípios, para os respectivos anos analisados. Em geral, os municípios de Campestre do Maranhão, Porto Franco e Estreito foram os que sofreram as maiores variações (os dois primeiros com 35\%, e o terceiro com $24 \%$ de redução da vegetação nativa, respectivamente). Entretanto, os dados demonstram que todos os demais municípios deste estado vêm sofrendo uma elevada pressão antrópica, em grande parte pela expansão de culturas agrícolas, pecuária (bovina) e ações ilegais de desmatamentos.

Tabela 5 - Quantificação da vegetação remanescente (INR) para os anos de 1980 e 2006, nos municípios envolvidos por empreendimentos hidroelétricos no Estado do Maranhão.

\begin{tabular}{l|c|c|c|c|c}
\hline \multirow{2}{*}{ MUNICÍPIOS } & \multicolumn{2}{|c|}{1980} & \multicolumn{2}{c}{2006} \\
\cline { 3 - 6 } & Área mun. (ha) & Veg. nativa (ha) & $\%$ & Veg. nativa (ha) & $\%$ \\
\hline Campestre do Maranhão & 61.820 & 46.799 & 76 & 24.268 & 39 \\
\hline Carolina & 649.000 & 321.216 & 49 & 274.508 & 42 \\
\hline Estreito & 272.770 & 201.219 & 74 & 137.719 & 50 \\
\hline Porto Franco & 142.250 & 119.276 & 84 & 69.430 & 49 \\
\hline Ribamar Fiquene & 73.840 & 68.848 & 93 & 52.050 & 70 \\
\hline Total & 1.199 .680 & 757.358 & 63,13 & 557.975 & 46,51 \\
\hline
\end{tabular}




\section{Estado do Pará}

Dos municípios envolvidos por empreendimentos hidroelétricos no Estado do Pará (Tabela 6), pode-se verificar que Marabá se destaca neste período (1980 - 2006) pela maior redução da cobertura vegetal nativa, de $12 \%$, enquanto para os demais municípios tal redução não ultrapassou $7 \%$. Vale ressaltar que, em alguns municípios deste Estado houve um aumento da cobertura vegetal ao longo deste período (1980 - 2006), o que não representa, na mesma proporção, um avanço em termos ecológicos, pois esta cobertura é um indicativo de regeneração e reflorestamento. Estima-se que atividades agrícolas, pecuárias e projetos hidroelétricos sejam responsáveis por essas mudanças nos municípios mencionados.

Tabela 6 - Quantificação da vegetação remanescente (INR) para os anos de 1980 e 2006, nos municípios envolvidos por empreendimentos hidroelétricos no Estado do Pará

\begin{tabular}{l|c|c|c|c|c}
\hline \multirow{2}{*}{ MUNICÍPIOS } & & \multicolumn{2}{|c|}{1980} & \multicolumn{2}{|c}{2006} \\
\cline { 3 - 6 } & Área mun. (ha) & Veg. nativa (ha) & $\%$ & Veg. nativa (ha) & $\%$ \\
\hline Breu Branco & 398.900 & 226.557 & 66 & 305.6487 & 77 \\
\hline Itupiranga & 791.460 & 536.826 & 82 & 619.480 & 78 \\
\hline Jacundá & 201.480 & 181.745 & 47 & 124.585 & 62 \\
\hline Marabá & 1.515 .790 & 1.129 .337 & 81 & 1.042 .068 & 69 \\
\hline Novo Repartimento & 1.546 .410 & 1.064 .715 & 82 & 1.157 .892 & 75 \\
\hline São João do Araguaia & 130.170 & 93.133 & 74 & 87.377 & 67 \\
\hline Tucuruí & 209.550 & 141.465 & 61 & 141.834 & 68 \\
\hline Total & 4.793 .760 & 3.373 .778 & 77,60 & 3.478 .723 & 72,56 \\
\hline
\end{tabular}

\section{Estado do Tocantins}

Na tabela 7 pode-se visualizar as taxas de INR nos municípios de Tocantins e sua variação no período estudado. Em geral, boa parte dos municípios apresentaram uma queda na cobertura vegetal nativa. Entretanto, foram os municípios de Tupirama ( $24 \%$ de redução no INR), Filadélfia (13\%), Miracema do Tocantins (12\%) e São Salvador (11\%) que sofreram as maiores variações no INR nestes 26 anos de análise. Como nos demais estados, atribuí-se esta perda na cobertura do solo aos projetos hidroelétricos, agriculturas e pastagens. Várias pesquisas têm apontado para uma expansão das atividades agropecuárias neste Estado e em outros da região nordeste do país, indicando o surgimento de uma nova fronteira agrícola (SANO et al., 2008; FERREIRA et al., 2010).

É importante destacar que, em Tupirama, estudos complementares por sensoriamento remoto indicam que boa parte desta mudança ocorreu nos últimos 6 anos da análise (i.e., entre 2000 e 2006), sobretudo pela expansão das atividades agropecuárias. 
NERES, J. C. I.; FERREIRA, M. E.; SILVA JÚNIOR, N. J. da

Tabela 7 - Quantificação da vegetação remanescente (INR) para os anos de 1980 e 2006, nos municípios envolvidos por empreendimentos hidroelétricos no Estado do Tocantins

\begin{tabular}{|c|c|c|c|c|c|}
\hline \multirow[b]{2}{*}{ MUNICÍPIOS } & \multirow{2}{*}{ Área mun. (ha) } & \multicolumn{2}{|l|}{1980} & \multicolumn{2}{|l|}{2006} \\
\hline & & Veg. nativa (ha) & $\%$ & Veg. nativa (ha) & $\%$ \\
\hline Aguiarnópolis & 23.880 & 22.185 & 55 & 13.027 & 54 \\
\hline Babaçulândia & 191.640 & 110.676 & 55 & 104.433 & 54 \\
\hline Barra do Ouro & 111.110 & 63.486 & 56 & 63.629 & 57 \\
\hline Bom Jesus do Tocantins & 133.820 & 94.531 & 70 & 89.046 & 67 \\
\hline Brejinho do Nazaré & 172.890 & 69.842 & 45 & 64.818 & 37 \\
\hline Filadélfia & 199.650 & 109.116 & 62 & 100.910 & 51 \\
\hline Ipueiras & 81.650 & 38.807 & 57 & 41.051 & 50 \\
\hline Itaguatins & 82.770 & 45.343 & 58 & 51.670 & 62 \\
\hline Itapiratins & 124.100 & 69.135 & 67 & 77.707 & 63 \\
\hline Lajeado & 30.130 & 23.432 & 65 & 17.678 & 59 \\
\hline Maurilândia do Tocantins & 79.240 & 28.802 & 33 & 36.088 & 46 \\
\hline Miracema do Tocantins & 266.700 & 192.953 & 61 & 130.954 & 49 \\
\hline Palmas & 247.490 & 170.058 & 47 & 116.932 & 47 \\
\hline Palmerópolis & 171.020 & 128.583 & 63 & 83.354 & 49 \\
\hline Palmeirante & 247.230 & 88.471 & 37 & 101.911 & 41 \\
\hline Paraná & 1.216 .090 & 574.476 & 54 & 641.024 & 53 \\
\hline Pedro Afonso & 205.030 & 101.889 & 49 & 96.553 & 47 \\
\hline Peixe & 511.120 & 272.813 & 55 & 250.041 & 49 \\
\hline Porto Nacional & 446.410 & 251.982 & 43 & 174.569 & 39 \\
\hline São Salvador & 142.760 & 103.582 & 79 & 98.139 & 69 \\
\hline Tocantinópolis & 108.180 & 69.884 & 38 & 60.007 & 55 \\
\hline Tupirama & 71.580 & 34.095 & 42 & 17.470 & 24 \\
\hline Tupiratins & 89.910 & 32.039 & 35 & 27.761 & 31 \\
\hline Total & 4.954 .400 & 2.696 .180 & 52,94 & 2.458 .772 & 49,62 \\
\hline
\end{tabular}

\section{Avaliação dos Índices Socioeonômicos}

Traçando um paralelo ao surgimento dos empreendimentos hidroelétricos na bacia do Rio Tocantins, entre as décadas de 1980 e 2000, este trabalho analisou os mesmos Estados e municípios em função de alguns índices socioeconômicos, visando verificar as possíveis consequências (positivas e negativas) a partir do surgimento destes empreendimentos supracitados. Tais indicadores, referentes às décadas de 1991 e 2000, englobam o Índice de Desenvolvimento Humano - Municipal (IDH-M), Renda per capita, Proporção de pobres e GINI (Concentração de renda).

\section{Estado de Goiás}

No estado de Goiás, o estudo analisou os municípios inseridos na área de influência das usinas hidroelétricas de Serra da Mesa e Cana Brava, cujas terras foram parcialmente inundadas pelos respectivos reservatórios.

Com base no gráfico da figura 5, nota-se uma evolução na qualidade de vida estimada pelo IDH-M dos municípios envolvidos pelos empreendimentos. Essa evolução pode ser explicada pelos avanços sociais relativos ao acesso à educação, ao aumento da expectativa de vida e ao crescimento da renda. O município com o maior IDH-M foi Campinorte, enquanto Cavalcanti apresentou o menor IDH-M. 


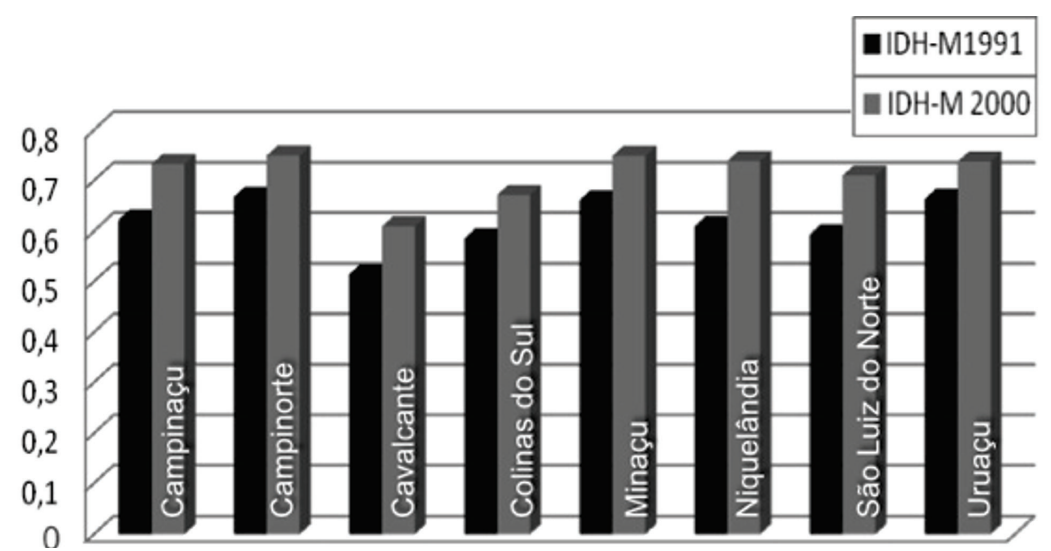

Figura 5 - Variação do IDH-M nos municípios envolvidos por empreendimentos hidroelétricos no Estado de Goiás, entre 1991 e 2000

Dentre os municípios analisados, Campinorte foi aquele com o maior crescimento de IDH-M, segundo o censo do IBGE de 2000, com um total de habitantes (no ano 2000) de 8.257. Entretanto, em relação ao ranking nacional, Campinorte ocupa apenas a $1864^{\circ}$ colocação, estando entre os municípios de médio desenvolvimento humano (IDH entre 0,5 e 0,8 ). Isto revela o fato de que este, assim como os demais municípios desta região, precisa (e pode) melhorar no quesito "qualidade de vida" para a sua população. O que elevou o crescimento do IDH-M de Campinorte foi a longevidade, seguido pela educação e renda. Avaliando-se os indicadores de renda de Campinorte, em fato verificou-se um decréscimo na proporção de pobres e no índice de Gini, conforme a tabela 8.

Tabela 8 - Indicadores de Renda, Pobreza e GINI para o município de Campinorte - GO, referentes aos anos de 1991 e 2000

\begin{tabular}{c|c|c}
\hline IndicadoreS & $\mathbf{1 9 9 1}$ & $\mathbf{2 0 0 0}$ \\
\hline Renda per Capita Média (R\$) & 116,27 & 167,99 \\
\hline Proporção de Pobres \% & 60,5 & 42,4 \\
\hline Índice de Gini & 0,59 & 0,56 \\
\hline
\end{tabular}

Fonte: PNUD - Atlas do Desenvolvimento Humano - 2002.

Já o município com o menor IDH-M, dentre aqueles com empreendimentos hidroelétricos, foi Cavalcante. Avaliando os indicadores de renda deste município, verificou-se uma melhora significativa na renda per capita média (em mais de 20\%). A proporção de pobres sofreu um decréscimo (queda de 7\%), enquanto o índice de Gini demonstra um pequeno aumento na desigualdade (Tabela 9).

Tabela 9 - Indicadores de Renda, Pobreza e GINI para o município de Cavalcante - GO, referentes aos anos de 1991 e 2000

\begin{tabular}{l|l|l} 
IndicadoreS & 1991 & 2000 \\
\hline Renda per Capita Média (R\$) & 70,57 & 91,50 \\
\hline Proporção de Pobres\% & 77,4 & 70,1 \\
\hline Índice de Gini & 0,55 & 0,63
\end{tabular}

Fonte: PNUD - Atlas do Desenvolvimento Humano - 2002.

\section{Estado do Maranhão}

Em 2000, o IDH-M para o Estado do Maranhão ficou com média de 0,636, sendo classificação pelo PNUD como uma região de médio desenvolvimento humano. Mesmo assim, observa-se 
no gráfico da figura 6 uma evolução em qualidade de vida estimada pelo IDH-M dos municípios envolvidos por empreendimentos. Estreito foi o município com maior IDH-M, enquanto o menor foi Ribamar Fiquené.

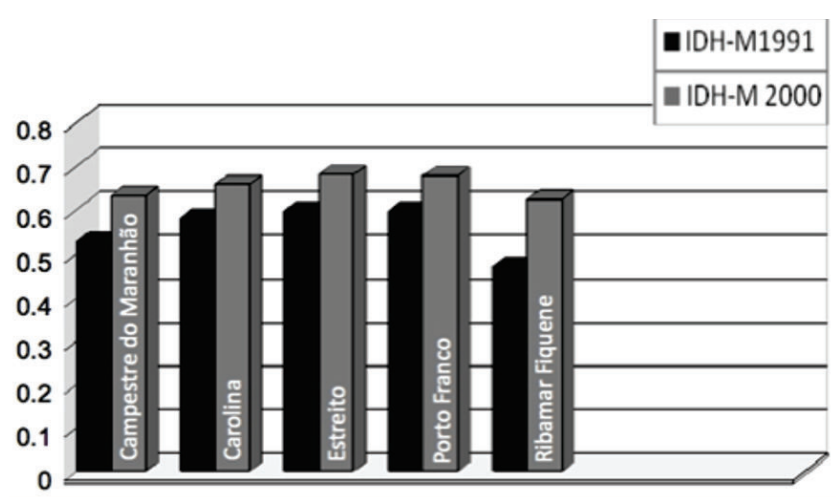

Figura 6 - IDH-M dos municípios envolvidos por empreendimentos hidrelétricos no Estado do Maranhão

Embora o município de Estreito, o qual apresenta um total de habitantes de 22.930 (IBGE, 2000), ocupe a primeira posição no ranking em relação aos outros municípios deste estado $(0,681)$, este valor é baixo quando comparado ao nível nacional, ficando este na $3279^{\circ}$ posição. Avaliando-se os indicadores de renda do município, verificou-se uma melhora na renda média per capita, um decréscimo na proporção de pobres, mas acompanhado também por um aumento no índice de Gini, o que equivale a um aumento na concentração de renda (Tabela 10).

Tabela 10 - Indicadores de Renda, Pobreza e GINI para o município de Estreito - MA, referentes aos anos de 1991 e 2000

\begin{tabular}{l|c|c}
\hline \multicolumn{1}{c|}{ Indicadores } & $\mathbf{1 9 9 1}$ & $\mathbf{2 0 0 0}$ \\
\hline Renda per Capita Média (R\$) & 91,53 & 127,09 \\
\hline Proporção de Pobres \% & 71,7 & 59,2 \\
\hline Índice de Gini & 0,46 & 0,57 \\
\hline
\end{tabular}

Fonte: PNUD - Atlas do Desenvolvimento Humano - 2002.

No outro extremo encontra-se o município de Ribamar Fiquené, com um desempenho muito baixo aos demais municípios no Maranhão envolvidos com empreendimentos de energia. Ainda que o município tenha apresentado um crescimento significativo, este não foi suficiente para tirá-lo do último lugar deste ranking. Avaliando seus indicadores de renda, houve uma melhora na renda per capita média, seguido por um decréscimo da proporção de pobres; mas o índice de Gini mostrou um aumento significativo, aumentando a desigualdade entre os habitantes deste município (Tabela 11).

Tabela 11 - Indicadores de Renda, Pobreza e GINI para o município de Ribamar Fiquené - MA, referentes aos anos de 1991 e 2000

\begin{tabular}{l|c|c}
\hline \multicolumn{1}{c|}{ IndicadoreS } & $\mathbf{1 9 9 1}$ & $\mathbf{2 0 0 0}$ \\
\hline Renda per Capita Média (R\$) & 72,82 & 85,80 \\
\hline Proporção de Pobres \% & 82,0 & 72,7 \\
\hline Índice de Gini & 0,46 & 0,57 \\
\hline
\end{tabular}

Fonte: PNUD - Atlas do Desenvolvimento Humano - 2002.

\section{Estado do Pará}

No ano de 2000, o IDH-M do estado do Pará teve média de 0,723, o que indica uma região de desenvolvimento médio, ocupando a $15^{\circ}$ posição no ranking nacional. Observa-se na figura 7 uma 
evolução em qualidade de vida estimada pelo IDH-M dos municípios envolvidos por empreendimentos do gênero. Neste grupo, o município com maior IDH-M foi Tucuruí $(0,755)$, enquanto o menor IDH-M foi obtido por São João do Araguaia $(0,582)$.

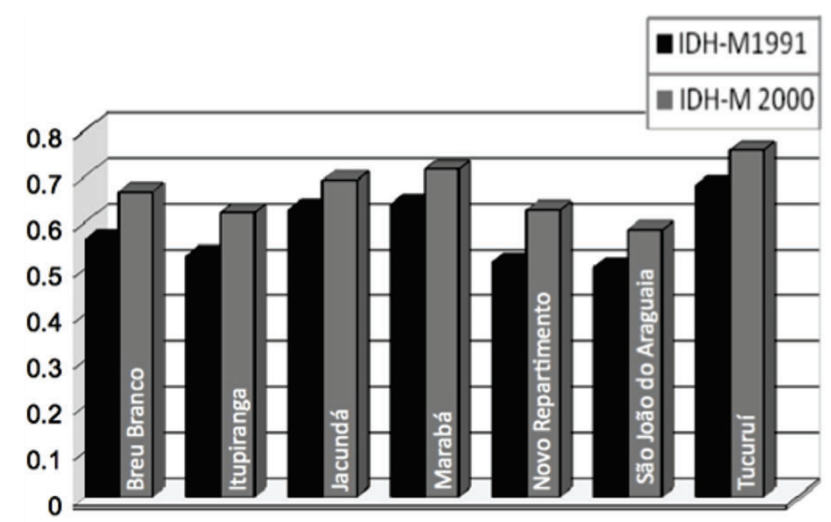

Figura 7 - IDH-M de 1991 e 2000 dos municípios envolvidos por empreendimentos hidrelétricos no do Estado do Pará

Sobre o município de Tucuruí, o qual apresenta um total de habitantes de 73.798 (1,19\% da população do Estado), este ocupa uma posição de destaque no IDH-M sobre os demais municípios envolvidos com empreendimentos hidroelétricos. Entretanto, o que elevou o crescimento deste município foi à longevidade, seguido pela educação e renda. Segundo a classificação do PNUD, o município está entre as regiões consideradas de Desenvolvimento Humano Médio. Analisando os indicadores, verificou-se um crescimento significativo na renda média per capita e um decréscimo na proporção de pobres; por outro lado, o índice de Gini (semelhantemente ao estado do Maranhão) aumentou de forma significativa, trazendo uma maior desigualdade econômica entre seus habitantes (Tabela 12).

Tabela 12 - Indicadores de Renda, Pobreza e GINI para o município de Tucuruí - PA, referentes aos anos de 1991 e 2000

\begin{tabular}{l|l|l} 
Indicadores & 1991 & 2000 \\
\hline Renda per Capita Média (R\$) & 132,02 & 180,99 \\
\hline Proporção de Pobres \% & 56,7 & 40,0 \\
\hline Índice de Gini & 0,58 & 0,59
\end{tabular}

Fonte: PNUD - Atlas do Desenvolvimento Humano - 2002.

Já o município de São João do Araguaia, com um total de habitantes de 12.247 (representando 0,2\% da população do Estado), e apesar de um crescimento satisfatório nos últimos anos, ainda não ocupa uma posição de destaque na classificação dos municípios envolvidos com tais empreendimentos. O que mais contribuiu para o crescimento de seu IDH-M foi a educação, seguido pela longevidade e a renda, classificado entre as regiões de desenvolvimento médio no país. Analisando os indicadores socioeconômicos, verificou-se uma queda na renda média per capita, um amento na proporção de pobres, seguido por um aumento no índice de Gini, indicando aumento na desigualdade entre seus habitantes (Tabela 13). 
Tabela 13 - Indicadores de Renda, Pobreza e GINI para o município de São João da Araguaia-PA, referentes aos anos de 1991 e 2000

\begin{tabular}{l|c|c}
\hline \multicolumn{1}{c|}{ Indicadores } & $\mathbf{1 9 9 1}$ & $\mathbf{2 0 0 0}$ \\
\hline Renda per Capita Média (R\$) & 75,85 & 67,72 \\
\hline Proporção de Pobres \% & 76,2 & 77,0 \\
\hline Índice de Gini & 0,55 & 0,62 \\
\hline
\end{tabular}

Fonte: PNUD - Atlas do Desenvolvimento Humano - 2002.

\section{Estado do Tocantins}

O Estado do Tocantins está localizado na região Norte do país, com uma área de 277.297 km2. Sua população em 2000 era de 1.157.098 habitantes, de acordo com o censo demográfico do IBGE para este ano, com IDH de 0,710. Segundo o PNUD (2002), o Estado está entre as regiões de desenvolvimento médio no Brasil, ocupando a $17^{\circ}$ posição no ranking nacional.

Observa-se que os municípios de Miracema do Tocantins e Palmas apresentam os melhores índices de IDH-M, enquanto o município de Tupirama detém o menor IDH-M entre os municípios relacionados neste estudo. Com a evolução do município de Tupirama, entre 1991 e 2000, o município de Babaçulândia passou a figurar em último lugar no ranking no ano de 2000 (Figura 7).
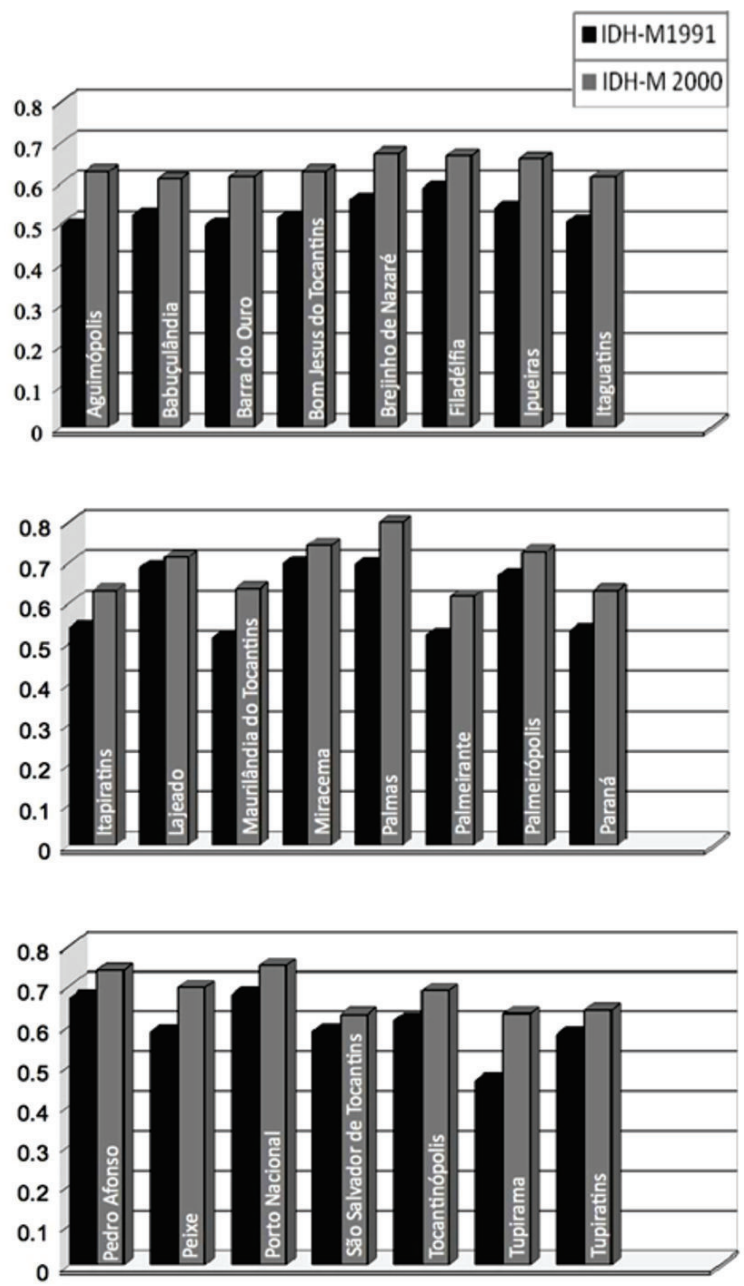

Figura 8 - IDH-M de 1991 e 2000 dos municípios envolvidos por empreendimentos hidroelétricos no Estado do Tocantins. 
Como pode ser observado na tabela 14, Babaçulândia, cuja população em 2000 era de 10.329 habitantes, obteve um crescimento econômico de 16,41\% entre 1991 e 2000, com um decréscimo na proporção de pobres e um aumento no índice de Gini (i.e., maior desigualdade entre a população).

Tabela 14 - Indicadores de Renda, pobreza e GINI para o município de Babaçulândia - TO, referentes aos anos de 1991 e 2000

\begin{tabular}{c|c|c} 
Indicadores & 1991 & 2000 \\
\hline Renda per Capita Média (R\$) & 60,18 & 74,14 \\
\hline Proporção de Pobres \% & 81,5 & 71,7 \\
\hline Índice de Gi ni & 0,50 & 0,57
\end{tabular}

Fonte: PNUD - Atlas do Desenvolvimento Humano - 2002.

Num outro extremo figura o município de Palmas, cuja população em 2000 era de 137.355 habitantes. Palmas é classificada como uma região de Alto Desenvolvimento Humano (IDH superior a 0,8), ocupando a primeira posição no Estado de Tocantins. Entre 1991 e 2000, o município teve um crescimento na renda per capita, seguido por uma redução na proporção de pobres e um aumento na desigualdade, já que o índice de Gini cresceu nos últimos anos (Tabela 15).

Tabela 15 - Indicadores de Renda, Pobreza e GINI para o município de Palmas - TO, referentes aos anos de 1991 e 2000

\begin{tabular}{l|c|c}
\hline \multicolumn{1}{c|}{ IndicadoreS } & $\mathbf{1 9 9 1}$ & $\mathbf{2 0 0 0}$ \\
\hline Renda per Capita Média (R\$) & 233,04 & 358,05 \\
\hline Proporção de Pobres \% & 40,9 & 24,3 \\
\hline Índice de Gini & 0,63 & 0,65 \\
\hline
\end{tabular}

Fonte: PNUD- Atlas do Desenvolvimento Humano - 2002.

A partir destes levantamentos, e apesar do IDH-M ter aumentado em praticamente todos os municípios de Tocantins, ainda existe uma significativa desigualdade entre estes, inclusive quando comprados com municípios de outros estados brasileiros, principalmente no Centro-Sul e Sudeste (onde o IDH já ultrapassa o patamar de 0,8 , numa escala de 0 a 1). Entretanto, essas informações demonstram que muitos avanços foram obtidos, principalmente ao se reduzir o número de municípios que estavam em um patamar de baixo desenvolvimento humano.

Por outro lado, faz-se necessário o estabelecimento de ações sistemáticas para a redução das diferenças socioeconômicas constatadas até aqui, tais como a geração de renda, a criação de novos postos de trabalhos, a expansão dos serviços públicos (como educação e saúde), medidas estas que precisam ser metas permanentes dos gestores públicos nos 43 municípios de Tocantins inseridos na área de estudo (com usinas hidroelétricas).

\section{CONSIDERAÇÕES FINAIS}

De uma forma geral, considerando-se todos os estados/municípios avaliados neste estudo (Estados de Goiás, Tocantins, Pará e Maranhão), aqueles inseridos no Maranhão foram os que apresentaram as maiores desigualdades sociais, mesmo quando da presença de empreendimentos hidroelétricos. Nos demais estados, como Tocantins, observou-se que o Índice de Desenvolvimento Humano - Municipal de tais municípios com empreendimentos hidroelétricos apresentaram crescimento econômico e social entre os anos de 1991 e 2000.

Em muitos casos, a qualidade de vida nestes municípios, sobretudo daqueles mais pobres, depende de serviços ambientais só encontrados em áreas de meio ambiente equilibrado, tal como o acesso a água potável, a uma flora e fauna preservada, a solos férteis, entre outros. 
A construção tão somente de usinas hidroelétricas não é garantia de benefícios sociais, apesar de verificarmos uma associação das mesmas com o desenvolvimento local dos municípios. Deve-se considerar, ainda, que tais empreendimentos trazem sérios impactos ambientais, como a criação de grandes áreas alagadas e a mudança no ciclo de vida destes rios represados (ressalta-se aqui uma maior emissão de Metano, um gás de efeito estufa). Em termos econômicos, as usinas hidroelétricas trazem royalties para os municípios, o que pode acelerar (não necessariamente) as melhorias sociais para a população local, tais como o acesso à educação, saúde e, por que não, energia elétrica.

Uma vez que os serviços ambientais mencionados tendam a ser comprometidos com a implantação de empreendimentos hidroelétricos (de pequeno, médio ou grande porte), juntamente com outras atividades de cunho agropecuário, torna-se essencial a realização de um ordenamento territorial por parte dos Estados e municípios, já realizado para outras atividades humanas de grande impacto socioambiental (como as de cunho industrial e agrícola), optando-se sempre pelas áreas de menor sensibilidade em termos ecológicos, ou mesmo por outros projetos com fontes de energia limpa e renovável, tais como a solar e a eólica.

Por fim, espera-se que este estudo oriente a adoção de políticas públicas voltadas para a minimização dos impactos gerados pelas usinas hidroelétricas, tanto na escala de bacias hidrográficas quanto na de estados e municípios. Outrossim, ressaltamos a necessidade de desenvolvimento de outras formas de geração de energia limpa, como a solar e a eólica, num momento em que se discute no país a expansão da matriz energética, ainda calcada no modelo hidroelétrico.

\section{AGRADECIMENTOS}

Agradecemos apoio do Laboratório de Processamento de Imagens e Geoprocessamento da Universidade Federal de Goiás e dos Geógrafos Genival Fernandes Rocha e Marlon Nemayer Pontes pela importante contribuição nas etapas de processamento e análise das imagens de satélite.

\section{REFERÊNCIA BIBLIOGRÁFICA}

ANEEL. BIG - Banco de Informações de Geração. 2007. Disponível em: http: <//www.aneel.gov.br/ aplicaçoes/capacidadebrasil>. Acesso em: 12/02/2007

ANA. Agência Nacional de Água. Plano estratégico do Tocantins-Araguaia - Brasil. 2006. Disponível em: <http://www.ana.gov.br $>$. Acesso em: 10/12/2007.

MME - Ministério de Minas e Energia. Plano de aceleração do crescimento - PAC. 2006. Disponível em: $<$ HTTP://www.mme.gov.br>. Acesso em: 28/06/2008.

COSTA, R. C., PRATES, C. P. O papel das fontes renováveis de energia no desenvolvimento do setor energético e barreiras à sua penetração no mercado. Rio de Janeiro: BNDES Setorial, 2005.

FERREIRA, M. E., MIZIARA, F., FERREIRA JÚNIOR, L. G., SOARES-FILHO, B. Land Cover Change Dynamics over the Brazilian Savanna: Future Scenarios and Perspectives of Conservation. In: The Meeting of the Americas - Foz do Iguaçu. EOS Transactions of the American Geophysical Union, v. 91, 2010.

IBGE. Mapa de biomas do Brasil. 2004. Disponível em: <http://mapas.ibge.gov.br/biomas2/viewer.htm>. Acesso em: 14/11/2006.

INPE. Instituto Nacional de Pesquisas Espaciais. 2007. Disponível em: $<$ http//www.obt.inpe.br/catalogo $>$. Acesso em: 20/12/2007.

MULLER, A. C. Hidrelétricas, Meio Ambiente e Desenvolvimento. São Paulo: Makron Books, 1995.

PNUD. Atlas do Desenvolvimento Humano no Brasil. 2002. Disponível em: <http//www.pnud.org.br/ atlas>. Acesso em: maio de 2007.

ROSA, L. P., SIGAUD, L., LA ROVERE, E. L., MAGRINI, A., POOPLE, A., FEARNSIDE, P. Estado, Energia Elétrica e Meio Ambiente: O Caso das Grandes Barragens. COOPE/UFRJ, 1995. 
SANO, E. E., ROSA, R., BRITO J. L., FERREIRA, L. G. Mapeamento semidetalhado (escala de 1:250.000) da cobertura vegetal antrópica do bioma Cerrado. Pesquisa Agropecuária Brasileira, v. 43, n. 1, p. 153$156,2008$.

Trabalho enviado em outubro de 2011

Trabalho aceito em dezembro de 2011 